\title{
The Effect of Moderate Temperatures on Latent Fingerprint Chemistry
}

\author{
Andrew Johnston and Keith Rogers
}

(S)AGE

\begin{abstract}
The effect of moderate temperatures $\left(25-75^{\circ} \mathrm{C}\right)$ on latent fingerprints over a five-hour period was examined using Fourier transform infrared (FT-IR) microspectroscopy. The aim of the study was to detect changes in IR spectra due to any changes in fingerprint chemistry; these results were then compared to pure compounds found in sebum that was subjected to $75^{\circ} \mathrm{C}$ for $5 \mathrm{~h}$. Latent fingerprints deposited on $\mathrm{CaF}_{2}$ microscope slides and placed on a Peltier pump heating stage showed that higher temperatures significantly reduced the quantity of sebaceous compounds after $5 \mathrm{~h}$, whereas temperatures below $45^{\circ} \mathrm{C}$ had little effect on the quantity of these compounds over the same time period. Fourier transform infrared microspectroscopy allowed for the real-time detection of changes to the IR spectra and demonstrated an increase in the $\mathrm{OH}$ stretch band $\left(3250 \mathrm{~cm}^{-1}\right)$ over $5 \mathrm{~h}$ at all temperatures investigated, suggesting various oxidation processes were taking place. Pure samples analyzed included squalene, fatty acids, wax esters, and mixed triglycerides. Unsaturated lipids showed a similar increase in the $\mathrm{OH}$ stretch band to the latent fingerprints whereas saturated compounds showed no change over time. This information is required to better understand the effect of moderate temperatures on latent fingerprints and how these temperatures could affect aged print composition.
\end{abstract}

\section{Keywords}

Fingerprints, Fourier transform infrared, FT-IR, microspectroscopy, aging, thermal degradation, decomposition, oxidation

Date received: 20 November 2016; accepted: 30 January 2017

\section{Introduction}

The chemical degradation of latent fingerprints post deposition is of great interest to the forensic community. It is well documented that the chemistry of latent prints changes temporally in both adults and children. ${ }^{1-4}$ These changes not only affect visualization techniques, ${ }^{5-7}$ some being more effective than others on aged prints, but also may potentially provide the basis for an aging tool to establish time since deposition.

The chemical components of a latent fingerprint have been well documented using a variety of analytical techniques ${ }^{8,9}$ but the chemical changes that occur over time are less well understood. Previous studies have shown that there are changes in fingerprint chemistry over time and under different conditions. Temporal decomposition ${ }^{10-15}$ appears to involve the shortening and degradation of unsaturated lipids including fatty acids (FA), wax esters, triglycerides, and squalene (SQ) due to various oxidation processes. ${ }^{16-20}$ In contrast, saturated lipids stay relatively stable over longer time periods ( $>60$ days). ${ }^{20}$ A change in unsaturated FA has been observed over time decreasing significantly over a 30-day period. ${ }^{12,20}$ This is due to the unsaturated moiety degrading through both aerobic and anaerobic processes and increasing the proportion of unsaturated compounds. ${ }^{20}$

Exposure to light also has a significant impact on fingerprint composition. Studies have shown that exposure to light affects the breakdown mechanisms of various components within fingerprint deposits differently and more rapidly than in dark conditions. Short chain FA and SQ in particular were affected by exposure to light conditions. ${ }^{2,13}$ Squalene degradation is supported by the identification of various photo-oxidation mechanisms to produce intermediary products including peroxides, hydroperoxides, and SQ epoxide and the fully oxidized forms being hexanedioic and pentanedioic acid. ${ }^{19,20}$ These products are particularly

Cranfield University, The Defence Academy of the United Kingdom, Shrivenham, UK

\section{Corresponding author:}

Andrew Johnston, Cranfield University, The Defence Academy of the United Kingdom, Shrivenham SN6 8LA, UK.

Email: a.johnston@cranfield.ac.uk 
prevalent when SQ is exposed to ultraviolet (UV) radiation, such as direct sunlight. ${ }^{19-21}$

Studies into the temporal changes of latent fingerprints, and exposure to light and dark conditions over time, are numerous and have indicated the complex nature of latent fingerprint chemistry. Studies into the effects of other environmental conditions on fingerprint chemistry, such as temperature, are also prevalent but these pyrolytic degradation studies mostly examine the effect of extreme temperatures $\left(>150^{\circ} \mathrm{C}\right)$ from exposure to fires, improvised explosive device (IED) detonations or spent ammunition cartridges. ${ }^{6,7,22-25}$ Studies on the effects of more moderate temperature variations on latent prints (from room temperature to $80^{\circ} \mathrm{C}$ ) are more limited ${ }^{26}$ but did demonstrate a general decrease in lipid components. ${ }^{26} \mathrm{In}$ contrast to previous studies, detailed examination of moderate temperature effects $\left(25-75^{\circ} \mathrm{C}\right)$ could provide significant information into the natural aging processes that occur within latent fingerprints.

Fourier transform infrared (FT-IR) spectroscopy is an emerging but recognized tool for forensic research applications. Previous studies have utilized IR techniques to successfully identify the key components of latent fingerprints, ${ }^{10,15,26-29}$ and FT-IR is ideally suited to the analysis of latent prints due to its nondestructive nature and specificity in identifying functional groups in organic compounds. Fourier transform infrared microspectroscopy has proven to be a powerful tool in monitoring temporal changes in latent fingerprints as specific sample areas can be repeatedly analyzed over the duration of an experiment. ${ }^{26,27}$

The aim of this study was to investigate the immediate effects of elevated temperatures $\left(25-75^{\circ} \mathrm{C}\right)$ on the organic compounds within latent fingerprints from 0 to $5 \mathrm{~h}$ since deposition. Given the known oxidation processes that occur post deposition of a latent print, this study also aimed to analyze any changes in the IR spectra that could allude to these processes taking place within the first few hours since deposition. The work was strengthened through the examination of temperature effects on individual chemical components found within latent fingerprints thus enabling a more robust interpretation of observed changes. The compounds selected were either the most abundant in their group, e.g., serine shown to be the most abundant amino acid, ${ }^{30-32}$ or known to have a significant effect on fingerprint degradation, i.e., SQ. ${ }^{|6-2|}$ The individual components investigated were the steroid precursor SQ, the FA palmitic acid (saturated), linoleic acid (polyunsaturated), the amino acid serine, the ester myristyl myristate, and mixed saturated and unsaturated triglycerides. These compounds were selected to crudely represent the major components within a latent fingerprint and as a representative for each of the essential functional groups under investigation in this study.

\section{Experimental}

\section{Sample Preparation}

All sample fingerprints were obtained from a single donor (a single donor was used for this small-scale study to maintain a relative consistency between samples, thus any notable observations were likely to be from the variations in temperature and not simply the inter-variability between fingerprints from multiple donors). Hands were first washed and dried thoroughly. The index finger was then drawn from the bridge of the nose, under the eye, to the temple ten times to collect sebaceous secretions and to simulate natural grooming behavior, and placed directly onto a $\mathrm{CaF}_{2}$ IR microscope slide $(10 \times 10 \mathrm{~mm}$, Crystran Ltd). All prints were deposited between 09:00 and 10:00 to avoid significant diurnal variations in composition of the latent prints. For each print, the same index finger was used. All fingerprints were destroyed at the end of each day and the process repeated for each additional print; this ensured prints were fresh and analysis was not of inadvertently aged prints.

\section{Heating of Fingerprints}

Once the prints were deposited onto the $\mathrm{CaF}_{2}$ slides, they were placed onto a hollowed-out Peltier pump heat stage and placed under the FT-IR microscope. The temperatures investigated were $25^{\circ} \mathrm{C}, 35^{\circ} \mathrm{C}, 45^{\circ} \mathrm{C}, 55^{\circ} \mathrm{C}, 65^{\circ} \mathrm{C}$, and $75^{\circ} \mathrm{C}$. Five prints were analyzed at each temperature, five deposits were selected for analysis per print, and spectra were acquired every hour for $5 \mathrm{~h}$ at relative humidity.

\section{Fourier Transform Infrared Microspectroscopy}

The latent fingerprints were analyzed using a PerkinElmer Spectrum Spotlight 200 FT-IR imaging System equipped with a liquid-nitrogen cooled MCT linear array detector. Data were analyzed using Perkin Elmer software, Spectrum (v. 10.02.00), and variations in spectra were processed using peak area calculations. Spectra from fingerprint deposits were collected in transmission mode, the IR beam passing through the slide and the hollowed center of the heat stage, within a $4000-750 \mathrm{~cm}^{-1}$ spectral range with ten scans per pixel at $4 \mathrm{~cm}^{-1}$ spectral resolution and $10 \mu \mathrm{m}$ spatial resolution, using a $100 \times 100 \mu \mathrm{m}$ aperture.

\section{Pure Sample Preparation}

The preparation consisted of $\mathrm{SQ} \geq 98 \%$ (Sigma Aldrich, UK), linoleic acid $\geq 99 \%$ (Sigma Aldrich, UK), serine $\geq 99 \%$ (Sigma Aldrich, UK), myristyl myristate $\geq 99 \%$ (Sigma Aldrich, UK), and mixed saturated and unsaturated triglycerides $\geq 98 \%$ (Sigma Aldrich, UK). A total of $10 \mu \mathrm{m}$ of the pure compound was pipetted onto a $\mathrm{CaF}_{2}$ slide and analyzed in an identical way to the latent fingerprints at $75^{\circ} \mathrm{C}$ 
for $5 \mathrm{~h}$. Analysis at this temperature allowed for a definitive indication as to whether these compounds were susceptible to thermal degradation.

\section{Results and Discussion}

Before any fingerprints were subjected to heat treatment, a control spectrum was obtained from each print. Figure I shows a typical FT-IR spectrum of a fresh fingerprint from this study, the key peaks in the range of $3000-1100 \mathrm{~cm}^{-1}$.

This study predominantly focused on variations in quantity of sebaceous materials at different temperatures. These sebaceous compounds correspond to the $2920 \mathrm{~cm}^{-1}$ and $2854 \mathrm{~cm}^{-1}$ antisymmetric and symmetric $\mathrm{C}-\mathrm{H}$ stretching modes of $\mathrm{CH}_{2}$ groups, the $\mathrm{C}=\mathrm{O}$ stretch of lipids $\left(174 \mathrm{I} \mathrm{cm}^{-1}\right)$, the scissoring mode of $\mathrm{CH}_{2}$ groups and antisymmetric $\mathrm{C}-\mathrm{H}$ bending mode of $\mathrm{CH}_{3}$ groups $\left(1463 \mathrm{~cm}^{-1}\right)$, the $\mathrm{CH}_{3}$ symmetric bend $\left(1380 \mathrm{~cm}^{-1}\right)$, the $\mathrm{C}-\mathrm{C}-\mathrm{O}$ stretch $\left(1160 \mathrm{~cm}^{-1}\right)$, and the $\mathrm{O}-\mathrm{C}-\mathrm{C}$ stretch $\left(1 \mathrm{III} \mathrm{cm}{ }^{-1}\right)$. Variations in quantity of eccrine secretions were also analyzed, amino acids were observed corresponding to the amide I band $\left(1655 \mathrm{~cm}^{-1}\right)$, and amide II band $\left(1545 \mathrm{~cm}^{-1}\right)$ of secondary amides. The broad $\mathrm{O}-\mathrm{H}$ stretch band $\left(3250 \mathrm{~cm}^{-1}\right)$ was also observed. It is changes to these sebaceous and eccrine absorption bands that correspond to changes in quantity of the related functional groups and therefore the compounds over time.

\section{Thermally Degraded Fingerprints}

Analysis of fingerprints exposed to moderate temperatures indicates significant changes in composition over time.

This study showed a significant reduction in absorbance, and therefore material, of all the key functional groups over the $5 \mathrm{~h}$ at $75^{\circ} \mathrm{C}, 65^{\circ} \mathrm{C}$, and $55^{\circ} \mathrm{C}$ with the exception of the amide bands, but no significant reduction at the lower temperatures of $45^{\circ} \mathrm{C}, 35^{\circ} \mathrm{C}$, and $25^{\circ} \mathrm{C}$ (Figures 2 and $3)$. This suggests that at the higher temperatures, the more volatile sebaceous substituents degrade rapidly, but at the lower temperatures $\left(45^{\circ} \mathrm{C}, 35^{\circ} \mathrm{C}, 25^{\circ} \mathrm{C}\right)$ there is less degradation over this short time period; certainly at $35^{\circ} \mathrm{C}$ and $25^{\circ} \mathrm{C}$ there is no observable change in absorbance between the control and after $5 \mathrm{~h}$. This is to be expected given the far longer time periods required for temporal degradation as observed in the studies mentioned previously, all being performed at room temperature. The reduction in sebaceous material at higher temperatures is understood to be due to the degradation through oxidation of lower molecular weight, volatile unsaturated lipids, including unsaturated FA, triglycerides as well as SQ. ${ }^{12,19,20}$ Squalene has been reported to break down rapidly in aged fingerprints reducing in quantity within one day and being almost entirely undetectable within one week, ${ }^{19}$ and this process it likely to be accelerated at elevated temperatures.

Figure 4 shows the rate of change in absorbance for the $2920 \mathrm{~cm}^{-1}, 2854 \mathrm{~cm}^{-1} \mathrm{C}-\mathrm{H}$ stretching modes of $\mathrm{CH}_{2}$ groups at all six temperatures. Samples heated to $45-75^{\circ} \mathrm{C}$ show a significant decrease in $\mathrm{C}-\mathrm{H}$ absorbance meaning a reduction in material, the fastest reduction in absorbance being at the highest temperatures. The slight increase in the $\mathrm{C}-\mathrm{H}$ stretching band at $35^{\circ} \mathrm{C}$ and $25^{\circ} \mathrm{C}$ could be an indication of an initial increase in short chain saturated FA as identified in previous studies, ${ }^{12}$ which at higher temperatures evaporate off due to their volatility.

The lack of change in the amide I and II bands (Figure 3) is unsurprising given previous research demonstrating that these compounds do not seemingly undergo any significant photo-degradation over time and thermal degradation is only seen with temperatures in excess of $100^{\circ} \mathrm{C} .{ }^{25}$

Most notable in this study was the significant increase in absorbance of the $\mathrm{OH}$ stretch band $\left(3250 \mathrm{~cm}^{-1}\right)$ across all

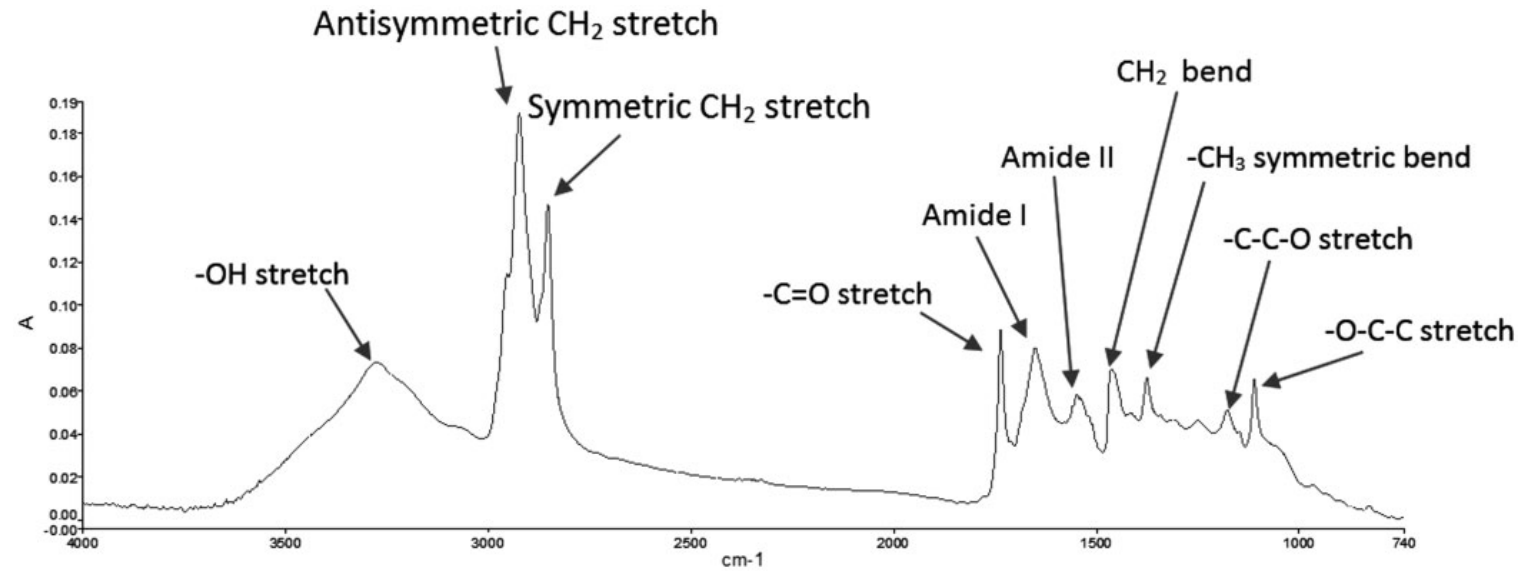

Figure I. Fourier transform infrared spectrum of a fresh fingerprint from study subject. 


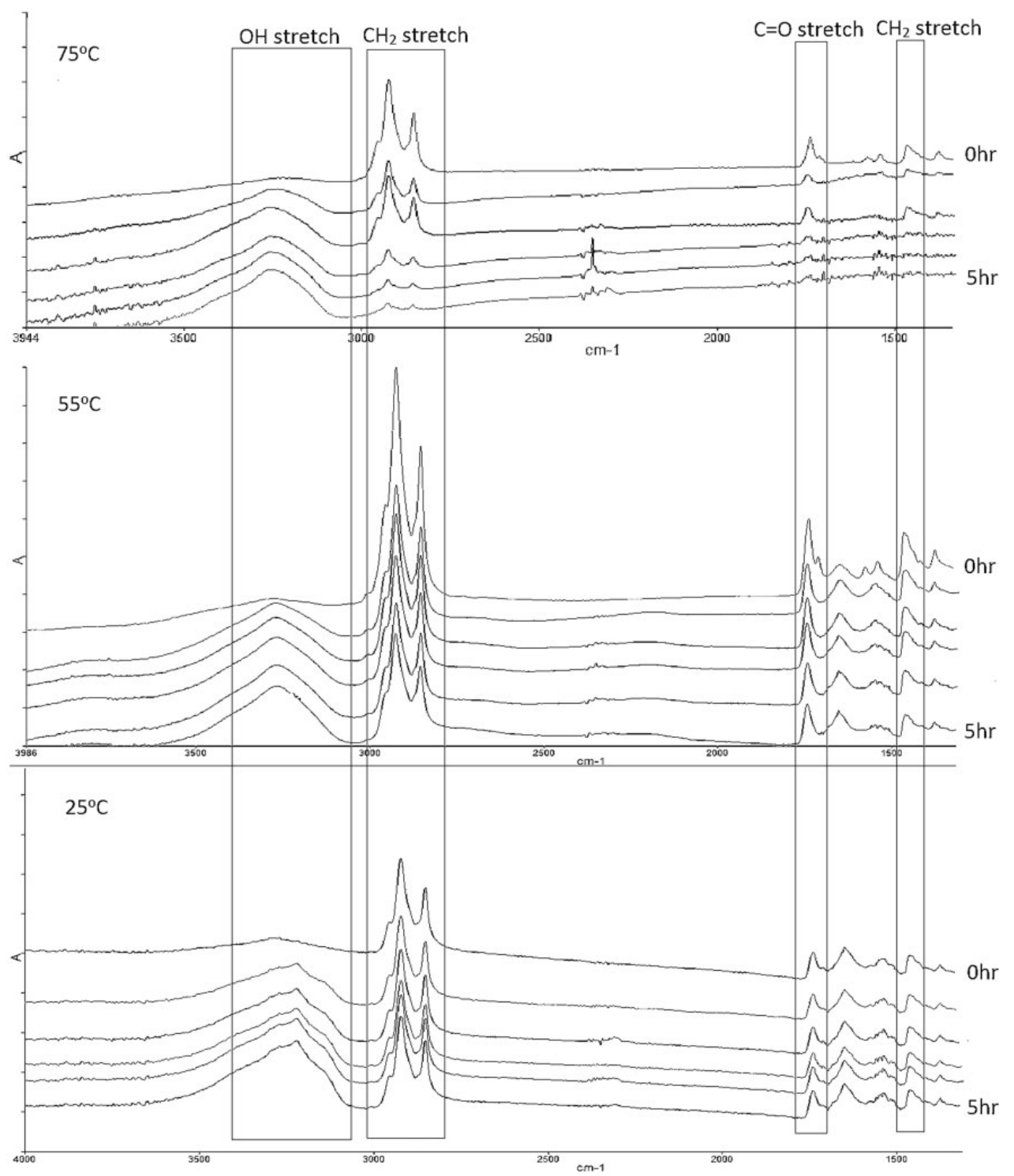

Figure 2. Absorbance spectra of latent fingerprints as a function of time and temperature for $75^{\circ} \mathrm{C}, 55^{\circ} \mathrm{C}$, and $25^{\circ} \mathrm{C}$.

temperatures. This is in contrast to previous temporal degradation studies that indicate a decrease in $\mathrm{OH}$ absorbance over time, ${ }^{15}$ thought primarily to be due to a loss of water through evaporation over periods as long as six weeks.

The rapid oxidation of sebaceous compounds such as unsaturated FA, SQ, and glycerides could account for the increase of the $\mathrm{OH}$ stretch absorption band. Even accounting for water loss, the net gain being the formation of these hydroxide functional groups due to oxidation mechanisms forming acids, alcohols, and hydroperoxides. ${ }^{12,19,20}$ This data suggests that the activation energies required for these processes are below $25^{\circ} \mathrm{C}$ as there was no statistical relationship between the rate of change for the increase in the $\mathrm{OH}$ stretch band over time and temperature. Given the previously reported rapid degradation of sebaceous compounds such as SQ and certain unsaturated FA, it is likely that these processes require a low activation energy for oxidation to occur. Although the temperatures tested in this study do not influence the rate of change of the $\mathrm{OH}$ absorption band, higher temperatures $\left(65^{\circ} \mathrm{C}\right.$ and $\left.75^{\circ} \mathrm{C}\right)$ do appear to limit the quantity of hydroxide functional groups being formed when compared to lower temperatures (Figure 3). This is most likely to be due to a more rapid loss of water at these higher temperatures as well as a loss of the more volatile organic compounds.

\section{Pure Compounds}

If specific sebaceous secretions are responsible for these oxidation processes and the resulting increase in the $\mathrm{OH}$ stretch band of the IR spectra, it is important to identify which compounds within these secretions are the main 

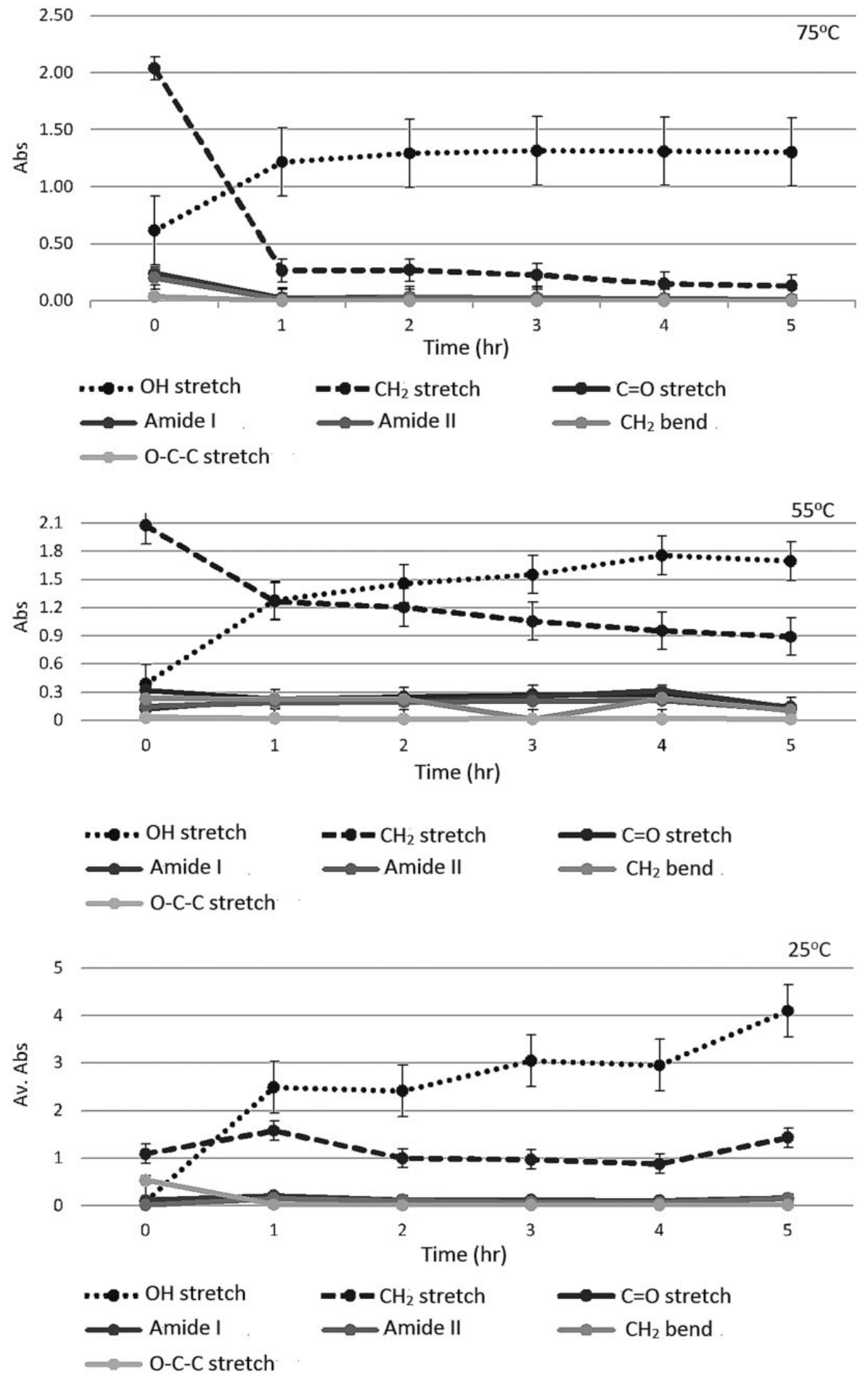

Figure 3. Changes in IR absorbance of key functional groups over time at $75^{\circ} \mathrm{C}, 55^{\circ} \mathrm{C}$, and $25^{\circ} \mathrm{C}$.

contributors to this change. As mentioned above, previous studies have demonstrated that certain unsaturated lipids decompose rapidly and could therefore contribute to the increase in absorbance of the $\mathrm{OH}$ band at $3250 \mathrm{~cm}^{-1}$. This study looked at the major components of a latent fingerprint to identify which pure compounds, such as $\mathrm{SQ}$, or compound groups, such as FA, most readily decomposed and contributed to the increase in absorbance of the $\mathrm{OH}$ band. Compounds primarily found in sebaceous secretions were selected, namely SQ, palmitic acid (saturated 


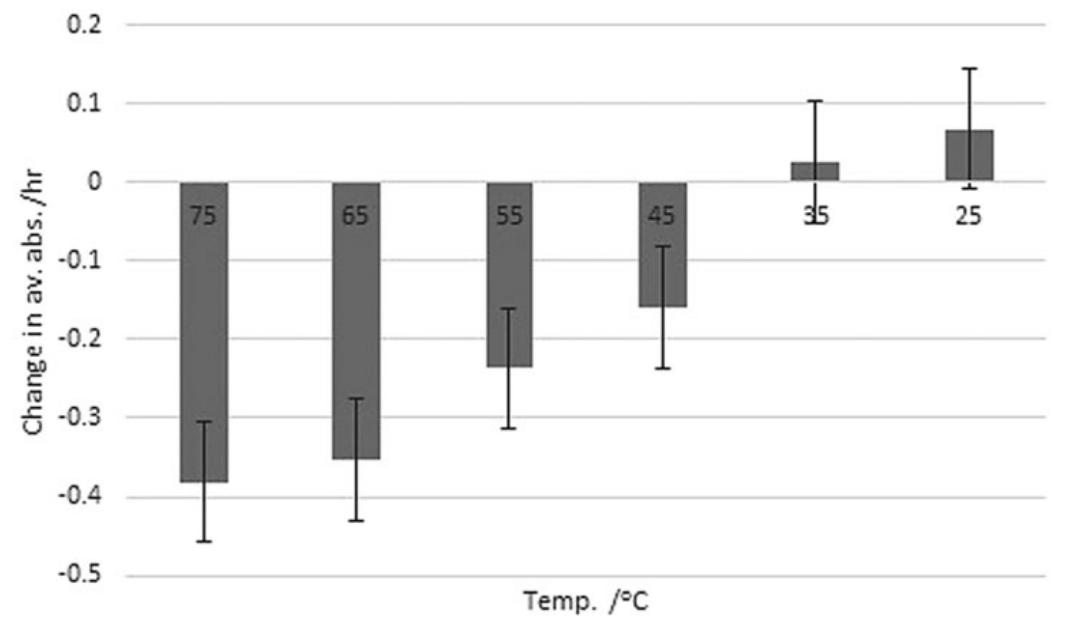

Figure 4. Rate of change of the $\mathrm{C}-\mathrm{H}$ stretch band absorbance at $75^{\circ} \mathrm{C}, 65^{\circ} \mathrm{C}, 55^{\circ} \mathrm{C}, 45^{\circ} \mathrm{C}, 35^{\circ} \mathrm{C}$, and $25^{\circ} \mathrm{C}$.

FA), linoleic acid (polyunsaturated FA), myristyl myristate (wax ester), and mixed triglycerides, as well as the amino acid serine, an eccrine secretion. Figure 5 shows an example spectra of the changes in the $\mathrm{OH}$ band over time for SQ.

Of the six compound groups investigated in this study (Figure 6), SQ, the mixed triglycerides, and linoleic acid showed significant changes in the $\mathrm{OH}$ stretch region at $3250 \mathrm{~cm}^{-1}$. Serine, palmitic acid, and myristyl myristate showed no significant changes over the duration of the experiment. These data suggest that thermal degradation processes impact unsaturated sebaceous compounds significantly, but not saturated sebaceous compounds or amino acids. The increase in the $\mathrm{OH}$ stretch region at $3250 \mathrm{~cm}^{-1}$ in SQ supports previous studies reporting the rapid oxidation of this compound to produce intermediaries such as alcohols, mono- and polyhydroperoxides, and finally hexanedioic acid and pentanedioic acid. The mixed triglycerides analyzed showed an increase in the $\mathrm{OH}$ stretch band over the $5 \mathrm{~h}$, indicating degradation processes in action, although not to the same extent as SQ (Figure 6). Some previous research has suggested possible triglyceride degradation mechanisms resulting in both saturated and unsaturated $\mathrm{FA},{ }^{33,34}$ the unsaturated FA then likely go through further oxidation thus continuing to increase the $\mathrm{OH}$ band. In a latent fingerprint, it is likely that triglyceride degradation processes would be increased due to the presence of cholesterol which has been shown to affect triglyceride decomposition. ${ }^{34}$ Of the FA analyzed, linoleic acid (Figure 6), a polyunsaturated FA, showed a rapid initial increase in the $\mathrm{OH}$ stretch region in the first hour, then little change over the remaining $4 \mathrm{~h}$. This suggests rapid oxidation occurring on this unsaturated compound perhaps, as previously proposed, to produce FA peroxides through aerobic degradation. ${ }^{36}$ It is worth remembering, however, that polyunsaturated FAs only make up $\sim 2 \%$ of sebaceous secretions ${ }^{17,36}$ so it is unlikely

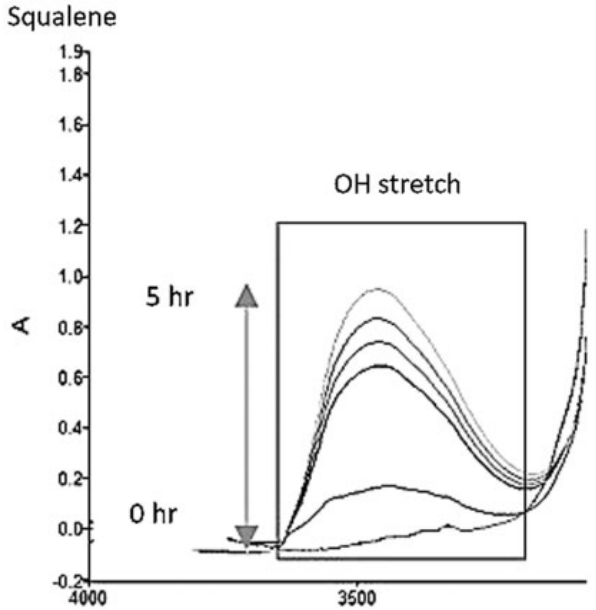

Figure 5. Infrared spectra of the $3250 \mathrm{~cm}^{-1} \mathrm{OH}$ stretch band of pure squalene heated to $75^{\circ} \mathrm{C}$ for $5 \mathrm{~h}$.

that these compounds would have a significant effect on the increase of the $\mathrm{OH}$ stretch band of a latent fingerprint. Monounsaturated FAs would also degrade aerobically however and they make up $\sim 48 \%$ of sebum. ${ }^{17,36}$ The $\mathrm{OH}$ stretch band of palmitic acid, a saturated FA, showed no significant variation in this study. This is consistent with temporal degradation studies reporting that $\mathrm{Cl} 6 \mathrm{FAs}$, such as palmitic acid, remain relatively stable over a 60-day period. ${ }^{20}$ The $\mathrm{OH}$ stretch band of myristyl myristate also showed no significant changes over the duration of this study, again consistent with previous studies showing that these saturated lipids are not significantly affected by temporal degradation due to a lack of functional groups. $^{17}$

Serine, the only non-sebaceous compound analyzed in this study showed no correlation between temperature and changes in the $\mathrm{OH}$ stretch region. As mentioned above previous studies have shown that significant thermal 

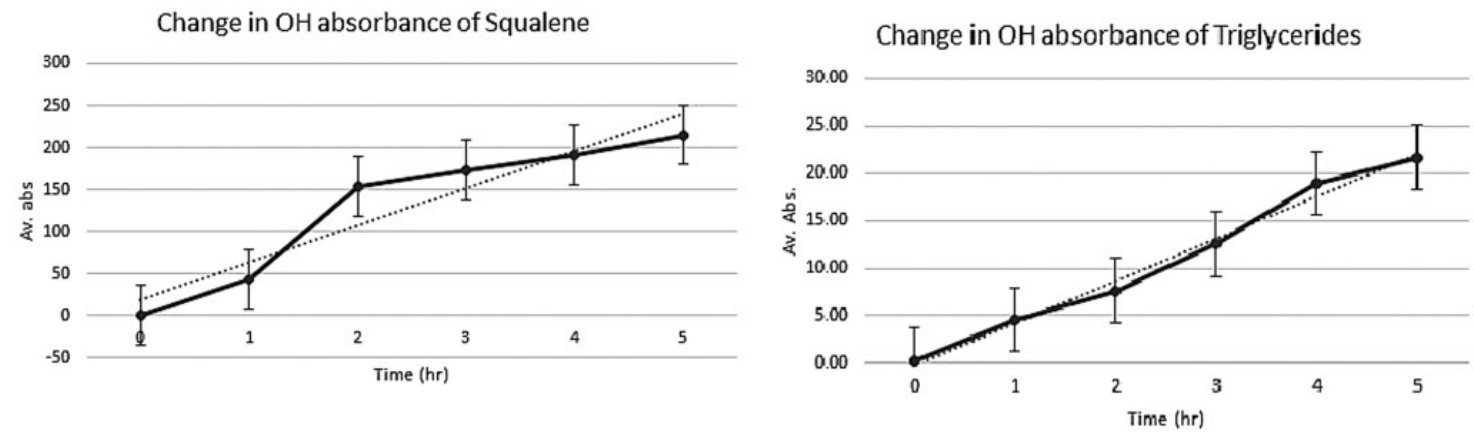

Change in $\mathrm{OH}$ absorbance of Myristyl Myristate (waxester)

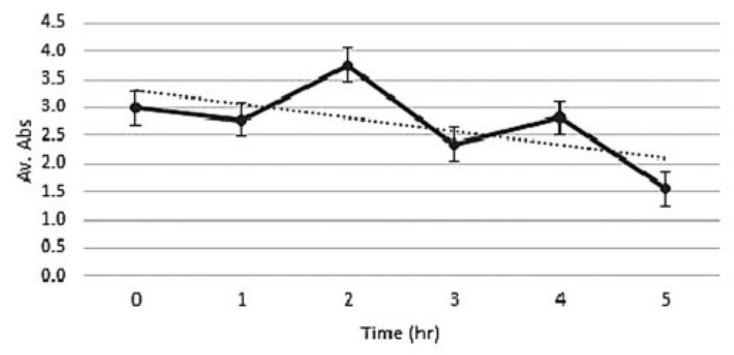

Change in $\mathrm{OH}$ absorbance of Palmitic Acid

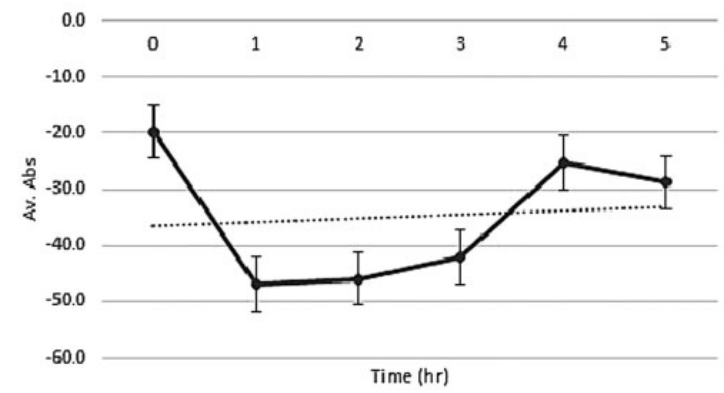

Change in $\mathrm{OH}$ absorbance of Serine

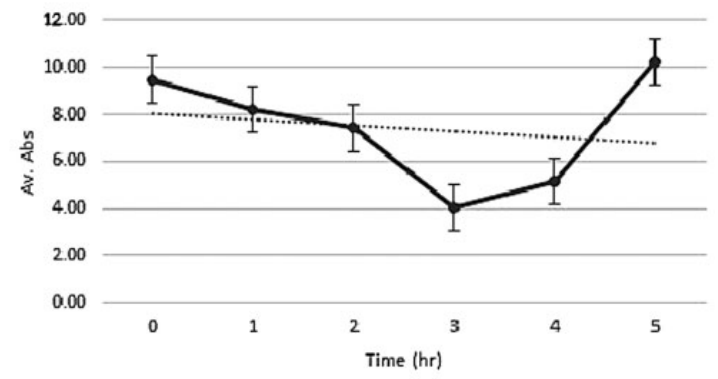

Change in $\mathrm{OH}$ absorbance of Linoleic Acid

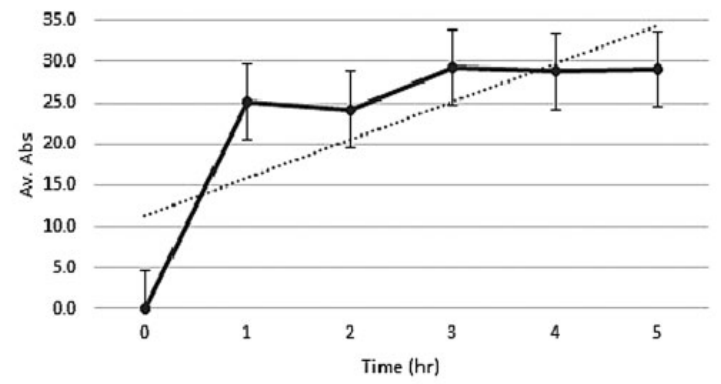

Figure 6. The increase in $\mathrm{OH}$ absorbance $\left(3250 \mathrm{~cm}^{-1}\right)$ of $\mathrm{SQ}$, mixed triglycerides, myristyl myristate, serine, palmitic acid, and linoleic acid at $75^{\circ} \mathrm{C}$ over $5 \mathrm{~h}$.

degradation of amino acids occurs at $100^{\circ} \mathrm{C}$ and higher 24,25 due to their low volatility, so it is not surprising that there were no significant changes in the $3250 \mathrm{~cm}^{-1} \mathrm{OH}$ band in this study.

\section{Conclusions}

The research presented within this paper suggests that the oxidation processes that occur during thermal degradation of latent fingerprints could be similar, if not identical, to that of temporal aging at a constant ambient temperature as shown in previous studies, ${ }^{12,16,19,20}$ but at a faster rate. It is reasonable to assume that latent fingerprints at a crime scene would be subject to varying diurnal temperatures from the time of deposition to the time of analysis by law enforcement agencies, varying from hours to days. This study demonstrates the dynamic nature of chemical decomposition within a fingerprint after just a few hours, higher temperatures causing more rapid degradation of the unsaturated and volatile lipids, which could impact crime scene work. Developing fingerprints that have been exposed to higher diurnal temperatures could be more challenging, particularly when using those developing agents that rely on lipophilic interactions. Further work is required to investigate the extent and consistency of these degradation processes using multiple donors to identify trends in decomposition, as well as the effect of different substrates on fingerprint chemistry. Future studies to better understand the degradation products that are likely to occur at varying temperatures could lead to better development techniques, more suited to prints subjected to higher diurnal temperatures.

The pure materials analyzed in this study translate to the compounds involved in the degradation processes of 
Applied Spectroscopy 0(0)

natural fingerprints. The analysis of pure samples that are present in sebum showed that $\mathrm{SQ}$, in particular, but also triglycerides and mono/poly-unsaturated FA, are most likely to be the cause of an increase in the $\mathrm{OH}$ stretch band at $3250 \mathrm{~cm}^{-1}$ over time. This is likely to be due to various intermediary and complete oxidation processes. Future work accounting for individual variability would provide a better understanding of the interactions between these compounds and how each component affects the stability of the other.

\section{Acknowledgments}

The authors thank the donor of the fingerprints residues for his contribution to this study.

\section{Conflict of Interest}

The authors report there are no conflicts of interest.

\section{Funding}

This research received no specific grant from any funding agency in the public, commercial, or not-for-profit sectors.

\section{References}

I. M.V. Buchanan, K. Asano, A.I. Bohanon. "Chemical Characterization of Fingerprints". Proc. SPIE 294I, Forensic Evidence Analysis and Crime Scene Investigation, 89. 1997. 294I: 89-95. doi: I0.III7/I2.266300.

2. D.K. Williams, C.J. Brown, J. Bruker. "Characterization of Children's Latent Fingerprint Residues by Infrared Microspectroscopy: Forensic Implications". Forensic Sci. Int. 20II. 206(I-3): |6I-165.

3. D. Noble. "Vanished into Thin Air: The Search for Children's Fingerprints". Anal. Chem. 1995. 67(I3): 435A-438A.

4. K.M. Antoine, S. Mortazavi, L.M. Miller. "Chemical Differences are Observed in Children's Versus Adults' Latent Fingerprints as a Function of Time". J. Forensic Sci. 2010. 55(2): 5/3-5I8.

5. K. Sampson, W. Sampson. "Recovery of Latent Prints from Human Skin". J. Forensic Identif. 2005. 55(3): 362-385.

6. A.G. Brown, D. Sommerville, B.J. Reedy, R.G. Shimmon, M. Tahtouh "Revisiting the Thermal Development of Latent Fingerprints on Porous Surfaces: New Aspects and Refinements". J. Forensic Sci. 2009. 54(I): ||4-12|.

7. A. Dominick, N. Nicdaeid, S. Bleay, V. Sears. "The Recoverability of Fingerprints on Paper Exposed to Elevated Temperatures, Part I: Comparison of Enhancement Techniques". J. Forensic Identif. 2010. 59(3): 325-339.

8. S. Cadd, M. Islam, P. Manson, S. Bleay. "Fingerprint Composition and Aging: A Literature Review”. Sci. Justice. 2015. 55(4): 219-238.

9. M.J. Bailey, N.J. Bright, S. Hinder, R.S. Croxton, S. Francese, et al. "Chemical Characterization of Latent Fingerprints by MatrixAssisted Laser Desorption lonization, Time-of-Flight Secondary lon Mass Spectrometry, Mega Electron Volt Secondary Mass Spectrometry, Gas Chromatography/Mass Spectrometry, X-ray Photoelectron Spectroscopy, and Attenuated Total Reflection Fourier Transform Infrared Spectroscopic Imaging: An Intercomparison". Anal. Chem. 2012. 84(20): 85।4-8523.

10. A. Girod, L. Xiao, B. Reedy, C. Roux, C. Weyermann. "Fingermark Initial Composition and Aging Using Fourier Transform Infrared Microspectroscopy (M-FT-IR)”. Forensic Sci. Int. 2015. 254: I85-196.
II. F. Cuthbertson, J.R. Morris. "The Chemistry of Fingerprints". AWRE Report No. 013/69. United Kingdom Atomic Energy Authority, 1969.

12. N.E. Archer, Y. Charles, J.A. Elliott, S. Jickells. "Changes in the Lipid Composition of Latent Fingerprint Residue with Time after Deposition on a Surface". Forensic Sci. Int. 2005. 154(2-3): 224-239.

13. R.S. Croxton, M.G. Baron, D. Butler, T. Kent, V.G. Sears. "Variation in Amino Acid and Lipid Composition of Latent Fingerprints". Forensic Sci. Int. 2010. 199: 93-102.

14. A. Girod, R. Ramotowski, C. Weyermann. "Composition of Fingermark Residue: A Qualitative and Quantitative Review". Forensic Sci. Int. 2012. 223(I-3): 10-24.

15. P. Fritz, W. Van Bronswjik, K. Lepkova, et al. "Infrared Microspectroscopy Studies of the Chemical Composition of Latent Fingermark Residues". Microchem. J. 2013. III: 40-46.

16. C. Weyermann, C. Roux, C. Champod. "Initial Results on the Composition of Fingerprints and its Evolution as a Function of Time by GC/MS Analysis". J. Forensic Sci. 201 I. 56(I): 102-108.

17. R. Ramotowski. "Composition of Latent Print Residues". In: H. Lee, R. Gaensslen (eds) Advances in Fingerprint Technology. London: CRC Press, 200I, pp.63-104.

18. R. Wolstenholme, R. Bradshaw, M.R. Clench, S. Francese. "Study of Latent Fingermarks by Matrix-Assisted Laser Desorption/lonisation Mass Spectrometry Imaging of Endogenous Lipids". Rapid Commun Mass Spectrom. 2009. 23(I9): 303 I-3039.

19. K.A. Mountfort, H. Bronstein, N. Archer, S.M. Jickells. "Identification of Oxidation Products of Squalene in Solution and in Latent Fingerprints by ESI-MS and LC/APCI-MS". Anal. Chem. 2007. 79(7): 2650-2657.

20. G.M. Mong, C.E. Petersen, T. Clauss. "Advanced Fingerprint Analysis Project-Fingerprint Constituents". Vol PNNL-13019. Pacific Northwest National Laboratory: U.S. Department of Energy 1999.

2I. M. Picardo, C. Zompetta, C. De Luca, et al. "Squalene Peroxides May Contribute to Ultraviolet Light-Induced Immunological Effects". Photodermatol. Photoimmunol. Photomed. 1991. 8(3): 105-II0.

22. C.M. Girelli, B.J.M. Lobo, A.G. Cunha, J.C.C. Freitas, F.G. Emmerich. "Comparison of Practical Techniques to Develop Latent Fingermarks on Fired and Unfired Cartridge Cases". Forensic Sci. Int. 2015. 250: 17-26.

23. W.W. Harper. "Latent Fingerprints at High Temperatures". J. Crim. Law Criminol. 1938. 29(4): 580-583.

24. A. Richmond-Aylor, S. Bell, P. Callery, K. Morris. "Thermal Degradation Analysis of Amino Acids in Fingerprint Residue by Pyrolysis GC-MS to Develop New Latent Fingerprint Developing Reagents". J. Forensic Sci. 2007. 52(2): 380-382.

25. G. De Paoli, S.A. Lewis, E.L. Schuette, L.A. Lewis, R.M. Connatser, et al. "Photo- and Thermal-Degradation Studies of Select Eccrine Fingerprint Constituents”. J. Forensic Sci. 2010. 55(4): 962-969.

26. C. Ricci, P. Phiriyavityopas, N. Curum, K.L. Andrew Chan, S. Jickells, et al. "Chemical Imaging of Latent Fingerprint Residues". Appl. Spectrosc. 2007. 6I(5): 5I4-522.

27. D.K. Williams, R.L. Schwartz, E.G. Bartick. "Analysis of Latent Fingerprints Deposits by Infrared Microspectroscopy". Appl. Spectrosc. 2004. 58(3): 3|3-3|6.

28. N.J. Crane, E.G. Bartick, R.S. Perlman, S. Huffman. "Infrared Spectroscopic Imaging for Noninvasive Detection of Latent Fingerprints". J. Forensic Sci. 2007. 52(I): 48-53.

29. A. Hemmila, J. McGill, D. Ritter. "Fourier Transform Infrared Reflectance Spectra of Latent Fingerprints: A Biometric Gauge for the Age of An Individual". J. Forensic Sci. 2008. 53(2): 369-376.

30. B. Hadorn, F. Hanimann, P. Anders, H. Curtius, R. Halverson. "Free Amino-Acids in Human Sweat from Different Parts of the Body". Nature. 1965. 215(99): 416-417.

31. P. Hamilton. "Amino-Acids on Hands". Nature. 1965. 205: 284-285. 
32. J. Oro, H. Skewes. "Free Amino-Acids on Human Fingers: The Question of Contamination in Microanalysis". Nature. 1965. 207(I): 1042-1045.

33. A. Srivastava, R. Prasad. "Triglycerides-Based Diesel Fuels". Renew. Sust. Energy Rev. 2000. 4(2): III-II3.

34. L. Iuliano. "Pathways of Cholesterol Oxidation via Non-Enzymatic Mechanisms". Chem. Phys. Lipids. 20II. 164(6): 457-468.

35. B.B. Dent, S.L. Forbes, B.H. Stuart. "Review of Human Decomposition Processes in Soil”. Environ. Geol. 2004. 45(4): 576-585.
36. A. Girod, C. Weyermann. "Lipid Composition of Fingermark Residue and Donor Classification Using GC/MS". Forensic Sci. Int. 20I4. 238: 68-82.

37. T. Atherton, R. Croxton, M. Baron, J. Gonzalez-Rodriguez, L. GámizGracia, A.M. García-Campańa. "Analysis of Amino Acids in Latent Fingerprint Residue by Capillary Electrophoresis-Mass Spectrometry". J. Sep. Sci. 2012. 35: 2994-2999. 